\title{
Virtual reality-integrated workflow in BIM- enabled projects collaboration and design review: a case study
}

Reza Zaker (D) and Eloi Coloma

\begin{abstract}
Introduction: A successful project delivery based on building information modeling (BIM) methods is interdependent on an efficient collaboration. This relies mainly on the visualization of a BIM model, which can appear on different mediums. Visualization on mediums such as computer screens, lack some degrees of immersion which may prevent the full utilization of the model. Another problem with conventional collaboration methods such as BIM-Big room, is the need of physical presence of participants in a room. Virtual Reality as the most immersive medium for visualizing a model, has the promise to become a regular part of construction industry. The virtual presence of collaborators in a VR environment, eliminates the need of their physical presence. Simulation of on-site task can address a number of issues during construction, such as feasibility of operations. As consumer VR tools have recently been available in the market, little research has been done on their actual employment in architecture, engineering and construction (AEC) practices.

Case description: This paper investigates the application of a VR based workflow in a real project. The authors collaborated with a software company to evaluate some of their advanced VR software features, such as simulation of an on-site task. A case study of VR integrated collaboration workflow serves as an example of how firms can overcome the challenge of benefiting this new technology. A group of AEC professionals involved in a project were invited to take part in the experiment, utilizing their actual project BIM models.
\end{abstract}

Discussion and evaluation: The results of the feedbacks from the experiment confirmed the supposed benefits of a VR collaboration method. Although the participants of the study were from a wide range of disciplines, they could find benefits of the technology in their practice. It also resulted that an experimental method of clash detection via simulation, could actually be practical.

Conclusion: The simulation of on-site tasks and perception of architectural spaces in a 1:1 scale are assets unique to VR application in AEC practices. Nevertheless, the study shows the investment in new hardware and software, and resistant against adoption of new technologies are main obstacles of its wide adoption. Further works in computer industry is required to make these technologies more affordable.

Keywords: Virtual reality, BIM, Collaboration, Visualization, AEC, Design, Simulation

\footnotetext{
* Correspondence: mr.zaker.h@gmail.com

Department of Architectural Technology, Universitat Politècnica de

Catalunya, Barcelona, Spain
} 


\section{Background}

The information and communication technology (ICT) revolution has affected many aspects of our lives today, and the construction industry has been no exception. It is constantly introduced to new tools and infrastructures that improve its practices. Among the tools for supporting advanced design planning include data-rich models, e.g. Building Information Modelling - which was already presented by Van Nederveen and Tolman (1992), though the original BIM concept can date back to 1970s (Eastman et al. 2011). Discussions on BIM often include arguments for collaboration across organizational boundaries. Some argue that new technologies (and BIM in particular) offer an opportunity to the paradigm shift of construction work practices (CURT 2005) while others suggest that successful adoption of BIM requires the technologies' changes to adapt to the current work of team members (Hartmann 2008). One of the new technologies that can be an integrated part of the BIM processes, is virtual reality. Only recently the available hardware and software available in market, allow for such an integration. That is the reason little research has been done in the field, and this paper investigates its adoption by AEC professionals through a case study. We examined a method of collaboration that could overcome the problem of the need for physical presence of collaborators, and could be easily integrated with daily practices. A problem associated with the use of VR in AEC, is the extra work and time it takes for visualizing a BIM model in VR. We collaborated with a software company that claims its VR tools could discard heavy works for visualizing a model in VR. By studying the current BIM models and workflows of a project under construction, we put into practice the use of VR for collaboration through the case study. Following the experiment, by semi structured interviews we learnt about the participants' experience during the workshop. Another purpose of the paper is the evaluation of some features of a VR software that allows for simulation of real life situation in a construction project. By this evaluation, we learnt that there are some benefits that are unique to VR, like the simulation of on-site tasks, that can bring great assistance to the AEC professionals.

\section{Theoretical background}

\section{BIM implementation in AEC}

BIM concept involved many processes and tools and different definitions have been suggested for it. Isikdag and Underwood (2010) defined BIM as the information management process throughout the lifecycle of a building which focuses on collaborative use of semantically rich 3D Building Information Models. The concept still remains relatively new for the industry, but attracts more attention and can achieve great improvement (McGraw-Hill Construction 2014). The numerous promising capabilities of
BIM throughout the whole lifecycle of a construction project, has encouraged architectural and engineering firms to move towards its adoption, despite the complication and expenses that are usually associated with it. The governmental mandates have been a pushing factor in some countries for its adoption, such as the UK Government that announced its "Government Construction Strategy" which included a mandate for the implementation of BIM Level 2 on all public projects by 2016 (BIM Task Group, 2013). This is along with many city and regional authorities that have been publishing and promoting their BIM guides such as New York city (BIM Guidelines 2012) and the community of Catalonia (CAT 2017). As pioneers in BIM adoption, North America has numerous AEC firms which have already been implementing BIM into their practice so that the BIM adoption in the region has been reported up to 70\% by 2012 (McGraw-Hill 2012). Therefore, the shift is already here and it is important to investigate the early results of employing these technologies and processes to pave the way for more mature adoptions in future.

\section{Social BIM}

Collaboration is a key factor for a successful project delivery, particularly in BIM enabled processes. With today's complicated jobs, the lack of a comprehensive and efficient collaborative workflow may cause delays, extra costs and a diminished project quality. Different methods have been suggested to improve collaboration and project delivery and It is well documented that these new mechanisms rely heavily on lean design and delivery processes and BIM tools (Eastman et al. 2011; Porwal and Hewage 2013). The innovative tools and technologies are making decision making processes and their communication to other stakeholders more efficient and coherent. Nevertheless, collaboration relies on broader aspects rather than just tools and technologies. With today's conventional methods in construction industry, different teams of various disciplines have been tending to work separately and pass their part to the next team only when they finalize their work. This results in workflow with collaboration while they are developing their project part. Though BIM aids collaboration amongst professionals in the AEC industry, merely utilizing dedicated BIM technologies by participants in a building project may not guarantee that collaboration is taking place or that such collaboration has been optimized. (Adamu et al. 2015). The social aspect of collaborative working is one which enables sense of community, democratic interaction, teamwork and leadership with ease of communication (Owen et al. 2006). Only by a true collaborative process it is possible that architects could be able to realize their design as intended with little unwanted changes caused by other disciplines often 
due to the lack of efficient communications during design stages. We can not underestimate the importance of motivated and persistent people and their social needs as they are the essential building blocks of good quality processes (Dave et al. 2008; Koskela and Kazi, 2003). People should be trained to have a collaborative mindset and break through the traditional barriers between different teams involved in a project.

BIM can be described as a socio-technical system (Sackey et al. 2014), because it is made up both of technical dimensions, e.g. 3d Modeling, and dimensions with social impact, e.g. process reengineering. The BIM trend has led to changes in the way designers and contractors work and collaborate, such as the way information is shared. (understanding effects of BIM) It is people (not systems) that collaborate, Hence, optimization of human efforts and resources would be critical for BIM, where it is postulated that designers should aggregate or produce a single BIM model in a central, integrated or federated location. (Adamu et al. 2015).

The environment in which collaboration sessions take place is a major factor determining the efficiency and success of collaborative workflows. A number of underlying processes, tools and technologies are fundamental to the success of a lean and BIM project, as has been demonstrated by some of the completed projects (Dave et al. 2013; Eastman et al. 2011). BIM model visualization technology is the core and engine around which most of BIM collaboration tools have been developed. Visualization is done by different methods and on different mediums, ranging from smart phones to rooms equipped with large screens such as the concept of BIM Big Room. The "Big Room" in construction refers to a large facility supporting the colocation of the entire project team, where some of the critical problems such as delays in decision-making, problems in communication, disparity in design iterations are eliminated. The Big Room framework has been proven to improve trust, collaboration and communication amongst stakeholders (Bushnell et al. 2013; Raisbeck et al. 2010). During such sessions, a member of each project teams and stakeholders are present in a room where on large screens, a coordination model is displayed and issues are addressed visually and by face to face dialogues that occur between project members, solutions are archived. However, today's practice of using "Big Room" has some challenges (Dave et al. 2013). A problem is that it demands the presence of project participants hence making it difficult specially for long-distance project teams.

In this paper, we evaluate a workflow based on virtual reality technologies, as the medium in which BIM models are visualized, where collaboration sessions can take place without the need of the physical presence of the project participants. BIM research needs to pay more attention to the people, process and their overarching interaction with technology (Liu et al. 2016), therefor participants' feedback was essential in this study. Social theory and behavioral science theory have been applied in understanding the decision-making processes of geographically dispersed design teams who used game-like virtual reality systems for collaboration (Goulding et al. 2014). People will be more encouraged to engage in collaborative workflows if such activates are of a more stimulating and amusing nature, in contrast with burdensome and mundane processes. The issue can be addresses by the use of more attractive activities, such as being in a VR environment.

\section{Virtual reality application in AEC}

It is not enough to see architecture; you must experience it (Rasmussen 1959). Since the 1980s, multiple efforts were made in order to develop and bring Virtual Reality (VR) technology to the masses. However, only in the last few years, one can truly admit that the technology enabling VR has been advanced to such an extent that renders its implementation both viable and worthwhile (Miltiadis 2016).

Virtual reality has the promise to provide the AEC professional with the ability to experience the project designs before they are built, as a digital duplication of the final product. An important prerequisite for the increased acceptance and use of CAD is an interface which will allow architects and engineers to create and interact with their digital designs more intuitively. VR, perhaps the most advanced of three-dimensional interfaces, has much potential for enhancing the way architects and designers interact with their digital models (Brooks 1993), and as many agree, VR has been proposed as a useful new tool for architects and designers (Schmitt 1993). As a medium, VR has three defining characteristics [1]. It is interactive (users can interact with models), spatial (models are represented in three spatial dimensions), and real-time (feedback from actions is given without noticeable pause) (Whyte 2002). With the ability to exploit and reuse information directly from the models, the current interdisciplinary collaboration can evolve towards integrated multi-disciplinary collaboration on models (Singh et al. 2011). Moreover, other attempts have been made to utilize VR for educating AEC professionals such as a proof-of-concept prototype that uses a game-like VR visualization interface supported by Mind Mapping (Pour Rahimian et al. 2014).

VR provides a spatio-visual representation of the design object and has the potential to become a highly effective instrument for exploration of digitally modeled architecture. The use of stereoscopic head-mounted displays (HMDs) allows stereovision and thus a depth perception in digital environments. The degree of immersion is directly related to image quality and the reaction rate of the HMD (Dörner et al. 2013). Because the computer records the head and body movements, the display responds to 
the user, giving the impression that he is immersed in the environment that surrounds him. The result is a spatio-temporal experience and the sense that the user is present in the virtual environment. This sense of presence is positively correlated with the user's level of interaction with the virtual world (Dörner et al. 2013). During the design process of a building, the outcome depends on the involved people's interpretations, perceptions, and prejudices (Colin and Hughes 2007). This is aligned with one of the main concepts of BIM, to involve the project stakeholders in early stages of the design, and VR can be an appropriate medium for this purpose.

A common case in construction projects is that some stakeholders are not from AEC sector, and have no familiarity with conventional construction documents. A prevalent problem is that the information and design concepts are not presented in such a way that all stakeholders can perceive them well. In this context, realtime visualizations and Virtual Reality (VR) have been shown to offer an efficient communication platform (Bouchlaghem et al. 2005; Roupé 2013). VR lets us experience and discuss something that doesn't yet exist with a common perspective. Instead of speaking in abstractions, virtual reality gives us a more tangible frame of reference. As a result, it tightens the understanding gap between clients and architects, and between visual and non-visual thinkers. (Bond 2017).

Another advantage of using VR during different stages of the project design development and construction, is its attraction for involving people. Many collaboration or project presentation session can be burdensome and boring to the participants. The act of wearing the Head mounted devices (HMDs) and being detached from the real world, can have something interesting about it for people, similar to the attraction of playing with arcades or other gaming devices. The disadvantages assumed to be associated with this method can be the physiological problems that it might cause, like motion or simulation sickness (Moss and Muth 2011). Feeling tired after a while wearing the HMDs or the struggle to get used to the environment and controls in the hand can also be negatively affecting the experience. This paper examines the validity of such problems by conducting a lived experiment. Considering the impact of BIM on construction industry, the importance of collaboration in BIM processes and the idea of social BIM and the opportunities of emerging technologies such as virtual reality for BIM collaboration, we found some space to be investigated. Therefore, we did a case study to examine and evaluate a BIM enabled collaboration and presentation session in VR to observe the behavior of participants and analyze their feedback taken by semi structured interviews.

\section{Case description}

The main objective of the case study was to evaluate a virtual environment where a design review, collaboration and project decision communication session could be conducted. The characteristics of the collaboration method included its fitting in the current workflows of the participants' firms. Therefore, the VR scene and related activities were based on the BIM models and processes the participants employ in the development of a project under construction in Barcelona at the time of our experiment. The focus of the case study was on the participants' experiences during the sessions in VR, their perception of the content that was presented to them with which they could interact in VR, their impression of the nature of VR, their comfort during the session and their final thoughts about its practicability in their everyday practice. For this reason, the hardware and software utilized during the experience were constant factors.

Two sessions were defined for the experiment. First was a mechanical, electrical and plumbing (MEP) systems coordination and design review and the second session was an architectural design review. Each session including different participants and activities.

\section{Method}

The phenomenological study was adopted for this research. The goal of qualitative phenomenological research is to describe a "lived experience" of a phenomenon. As this is a qualitative analysis of narrative data, methods to analyze its data must be quite different from more traditional or quantitative methods of research. (Waters 2016).

Data collection was performed by the description of participants of their lived phenomenal experience that was possible through conversations with them and semi structured interviews. Furthermore, a questionnaire was filled by the participants right after the experience. The reason for this was to document their first-hand impressions and feelings. We designed questions to be as less directive as possible, without suggesting or leading towards particular answers. We also tried to put together different types of question such as multiple choices, ratings and open answer question and the participants were also asked to describe freely their general impression of the experience. Moreover, we relied on qualitative data obtained by our direct observations during the session. Assuming that the phenomena of interest have not been purely historical, some relevant behaviors or environmental conditions will be available for observation. Such observations serve as yet another source of evidence in a case study (Yin 2009). As during the sessions other colleagues of the participants who were immersed in VR were present in the room, we also heard their observations. These were the main sources of the case study evidence; However, we should be aware that a complete list of sources can be quite extensive-including films, photographs, and videotapes; projective techniques and psychological testing; proxemics; kinesics; "street" ethnography; and life histories (Marshall and Rossman 1989). 


\section{The experiment Virtual environment}

To define the virtual environment, we initially had to evaluate the necessary tools, i.e. hardware and software capable of visualizing a BIM model in VR. Previous studies have found VR displayed on Oculus Rift DK2 Head Mounted Display (HMD) to be a promising media platform for visualizing and demonstrating complex spatial 3D models, especially for non-experts untrained in reading technical drawings (Kreutzberg 2015). At the time of the case study workshop, the commercial version of Oculus has been introduced to the market alongside other kits such as HTC VIVE. In terms of performance and quality the two products are pretty much rated in the same range (Swider 2017). They feature two OLED panels boasting a combined 2,160 $\times$ 1,200 resolution. Thus, each eye gets its own $1,080 \times$ 1,200 resolution display to mindlessly gaze at. With a $90 \mathrm{~Hz}$ refresh rate on both headsets and asynchronous spacewarp on the Rift for $90 \mathrm{fps}$ VR, this means there are 233 million pixels, making for a grown-up VR experience versus the $60 \mathrm{~Hz}$ Samsung Gear VR. HTC Vive and Oculus Rift also have a wider 110-degree field of view (measured diagonally). This results in a virtual reality world that is felt as if it truly wraps around one's head. The HTC VIVE headsets are slightly bigger in size and it's technically heavier at around $555 \mathrm{~g}$ without headphones included. Oculus is $470 \mathrm{~g}$ by comparison and throws in headphones.

Hence there was not a remarkable preference over one to another HMD for the purposes of our case study. We had the chance to use facilities of UPCschool, which is a division of Polytechnic university of Catalonia (UPC). We were given two HTC Vive devices and two high-end computers to handle the heavy task of the VR scene rendering. The two PC units were equipped with the following hardware: Intel $^{\odot}$ Core $^{\mathrm{TM}}$ i7-7700 K Processor (4-Cores, $8 \mathrm{MB}$ Cache, Turbo Boost 2.0, Overclocked up to $4.4 \mathrm{GHz}$, NVIDIA ${ }^{\circledR}$ GeForce $^{\oplus}$ GTX 1080 with 8GB GDDR5X 16GB DDR4 at $2400 \mathrm{MHz}$; up to 64GB (additional memory sold separately). These specifications are slightly higher than the characteristics of a desktop computer recommended by the HTC company (HTC, 2017) as the minimum hardware requirements for supporting its HMD. Today in the market there are several software available that are able to import geometry and information from different file formats utilized in AEC practice, and visualized them in a VR scene. Depending on the features and tools these software packages offer, users can have different sort of interactions with the model or scene. Therefore, to determine the suitable software for the case study we considered the software features and their required workflow for creating a VR scene, and the software used by the participants so that their file formats could work with the VR software. One of the software that currently has the most features for VR and is compatible with many file formats used by BIM enabled practices, is Fuzor. The most important features for the purposes of the case study were the ability to measure and move the model elements in the VR scene and the ability to host a multi-user collaboration session in VR. This means two or more users are able to be present in the same VR environment simultaneously through internet or LAN connection. Moreover, the performance and the ability to handle large models, and the graphic quality of the VR scene were considered for selecting the software among available choices in the market.

\section{The experiment agenda Participants}

We collaborated with CT engineers, an engineering firm from Barcelona, as they were part of a construction project for the government of Catalonia. They oversaw the BIM coordination and modeling of the MEP systems of the project, working with another firm which was in charge of the design and installation of the systems. The first part of the experiment involved a collaboration session in VR between these two parties. Members of the architectural discipline (Bttle i Roig) and of the development company (Hines) were invited to participate in the second session of the experiment, to conduct an architectural design review of the project.

The Catalonia government, whose project was utilized for the case study, encourages the application of BIM in its construction projects. It was a tremendous opportunity to involve one of their under-construction projects which is BIM enabled. The participants of the case study were the real stakeholders of this project called Campus Generalitat, an office building to host the new headquarters of the Catalonia government. The BIM models were being developed in Revit which then could be exported to the VR platform with its elements information, geometries and materials included in the model.

\section{BIM content}

The project is being developed by different stakeholders and firms. As the client required the delivery of the project in BIM, all the teams who were not already BIM enabled, had to collaborate with an external firm to develop the BIM model and implement the related processes for them. The project works had been divided in 10 parts or batches, 4 parts of which had been developed at the time of the experiment. The remaining parts whether did not require a BIM model or were not developed yet.

The models are coordinated in Autodesk Navisworks Manage 2017. To do this, the models in the formats RVT, NWC and IFC are merged weekly, and the IFC 
format is used to audit the models. CT engineers, uses 7 core models which eventually might become 11 to control the files size, plus 2 models prepared for printing and for inserting parameters using Dynamo (in the other 7). In addition, they use Navisworks both internally and externally to evaluate the work and resolve collisions.

After approval of all project stakeholders, we received 10 models most of which contained the MEP elements and we merged them with the main structure and architecture models to be placed in context. The total volume of these models were up to $2 \mathrm{~GB}$ and our computers could load them all as links (Fig. 1). Although the performance of Revit would become quite slow and difficult for interaction with the model. By installing the Fuzor VR collaboration software on the machine, it installs its plug-in on Revit which lets the user export the geometries to Fuzor to be visualized in VR. Almost 40 million polygons were exported to the platform from Revit which was a long and time consuming process, taking up to $50 \mathrm{~min}$. Once imported, the model can be saved in Fuzor file format (".CSV) which is then quick to load and using that file the user does not have to export the geometry every time. There is also a bidirectional synchronization between Revit and Fuzor meaning the changes done in either platform, will be reflected to the other one while synchronization is active. This feature prevents the need for re-exporting after every change.

As at the time of the experiment the project design was still in progress, only MEP systems of up to the third floor had been modeled in Revit. Figure 2 shows all the MEP related models loaded which exhibits its level of detail (LOD) and complexity. Review and coordination of such model can be a time taking and tough process and to visualize such a number of geometries high-end computers are required.

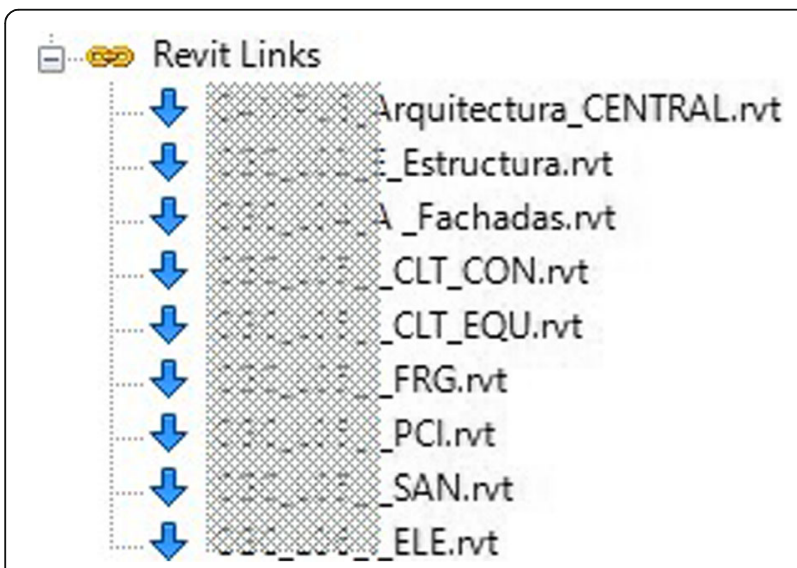

Fig. 1 Revit Tree showing loaded linked models. A federated model is used for BIM collaboration purposes. Models of different disciplines are linked in one of them for clash detection, model accuracy check and other purposes

\section{Tasks and processes}

Prior to the day of experiment, we met with some of the participants in four sessions in order to practice working with VR, revise the models, check the performance and prepare the hardware and software (Fig. 3). These measure were crucial to take in order to assure the experiment would go smooth and without problems and crashes. In the case of crashes and the obligation of restarting the platforms, we would have needed to cease the experiment for some time. Given the tight agenda and the timetable assigned to different participants during the day, it was important to avoid such incidents, as it is in real life meetings.

The case study had two main sessions, the first one was a MEP systems review that was led by the BIM modeler and was addressed to one the MEP installers. The two participants were immersed in VR in two rooms that were adjacent and there was a moveable partition wall between the two room. The partition had to be placed in such a way that the two pairs of HTC VIVE tracking sensors would not interfere with each other, yet the participants could hear each other and communicate verbally. In case of the participants being in distant location, Skype or similar tools could be used for communications.

As there was a high density of the mechanical equipment in one of the service rooms in -1parking level, the objective was to check the position and the space between the MEP elements in that room. This is especially important for the maintenance of these equipment which require regular inspections and replacements of the components. Viewing the model in 1:1 scale also allows for model checking itself and to find modelling errors which can affect the accuracy of data output from BIM models.

The two participants in this session collaborated in VR for about $20 \mathrm{~min}$, they appeared as avatars in the VR scene and could follow each other in the model and review the MEP systems (Figs. 4 and 5). It was evident that visualizing the model in VR could clarify some obscure parts of the project that are not clearly visible in conventional 2D drawings or even 3D scenes viewed by monitors.

One main advantage was that the participants could sit or move around the model and see pipework conditions that are difficult to realize otherwise by conventional review methods (Fig. 6).

They could see the installations together with the structure and architecture models loaded in the scene, which helped with the clash detection between the disciplines. The measurement tool allowed measuring the distance between two points to check the spaces necessary for maintained maneuvers (Fig. 7). The movement tool of the platform granted the participants the ability to move in the VR space the elements by selecting them with HTC VIVE joysticks which was a sort of simulation 


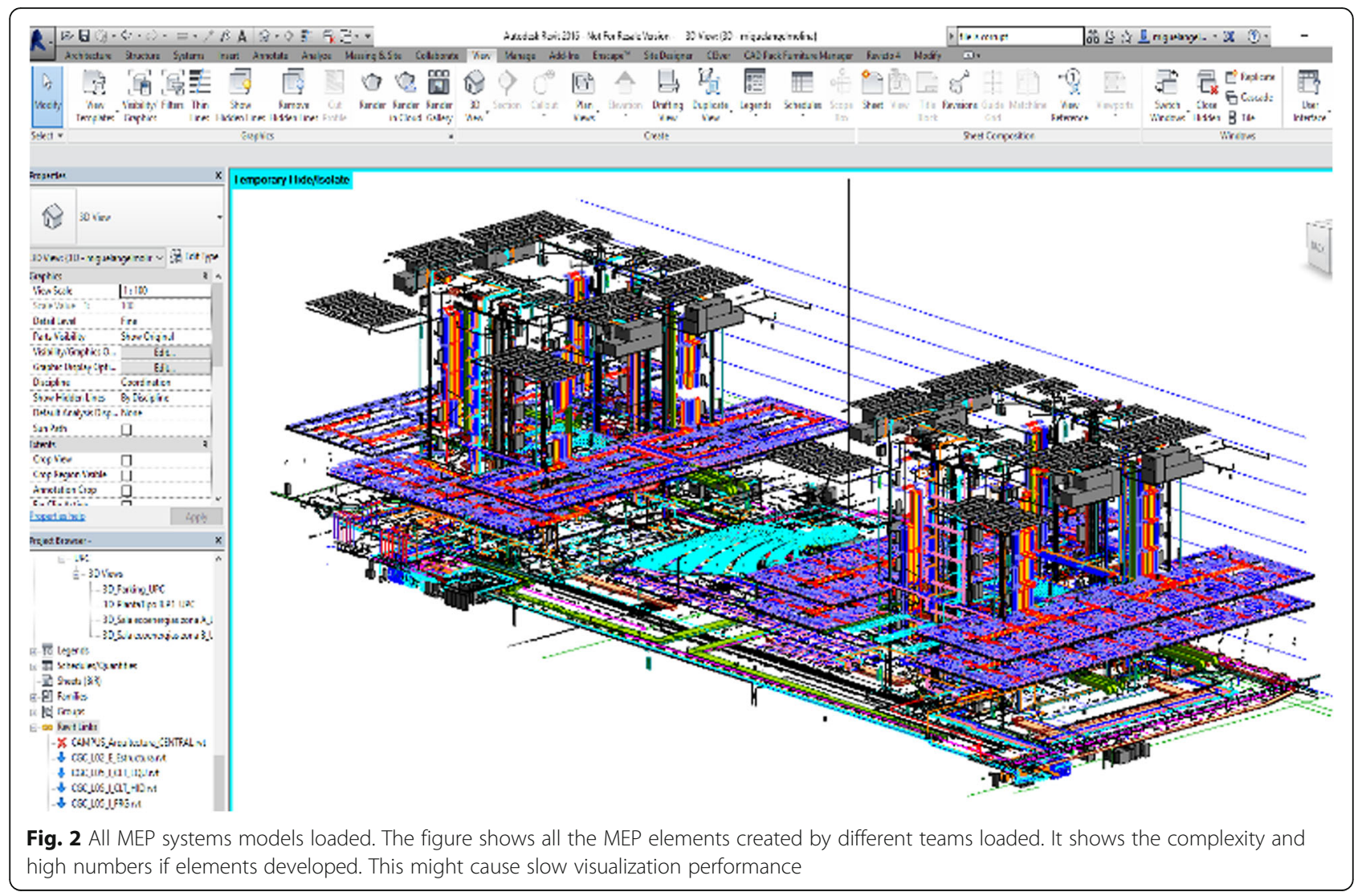

of a real component replacement procedure. The execution of this task with the joysticks was not quite facile and needed some precedent practice. These two main participants had practiced before the session started for about half an hour. Other colleagues of them who were present in the room then also tried the VR experience as well and were also interviewed later. This simulation of a real life situation in which the collaboration was taking place, could only be done in VR, and no other collaboration method.

The second session was focused on an architectural design review. The participants from the architecture team of the project and from the project development entity were immersed in VR to review the architecture design of the project. A part of the model was chosen for the session that included the entrance area with several voids and skylights, which was architecturally more interesting to be reviewed and experienced in VR (Figs. 8 and 9). Moreover, the exterior areas and facades and the entry to the building from the courtyard were reviewed. The architecture firm indicated that they do not load all the materials and textures on their Revit models, as it will increase the volume of the Revit files. This could cause an inferior performance of their computers. It is

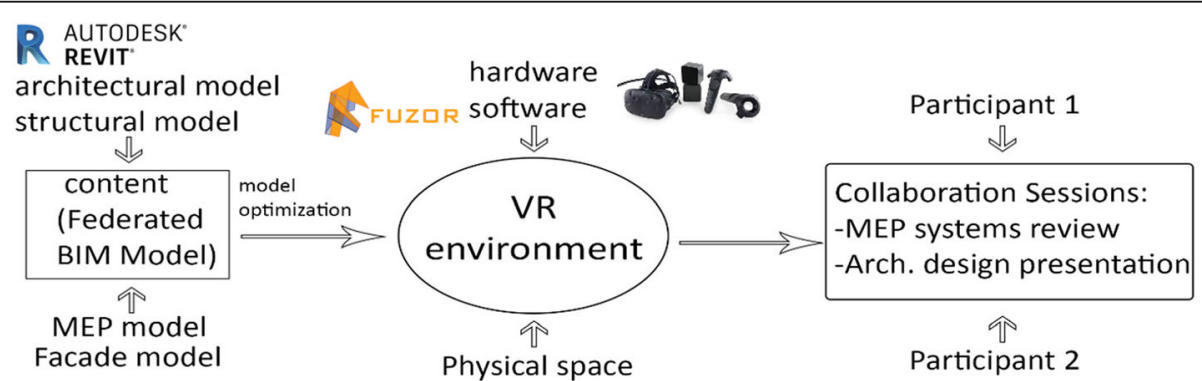

Fig. 3 The VR-integrated collaboration workflow. The figure shows different stages of the VR scene preparation for collaboration. Revit geometries are send in Fuzor platform to be visualized in VR on HTC Vive device. Multiple users can enter the VR environment simultaneously and perform a collaboration or presentation session 

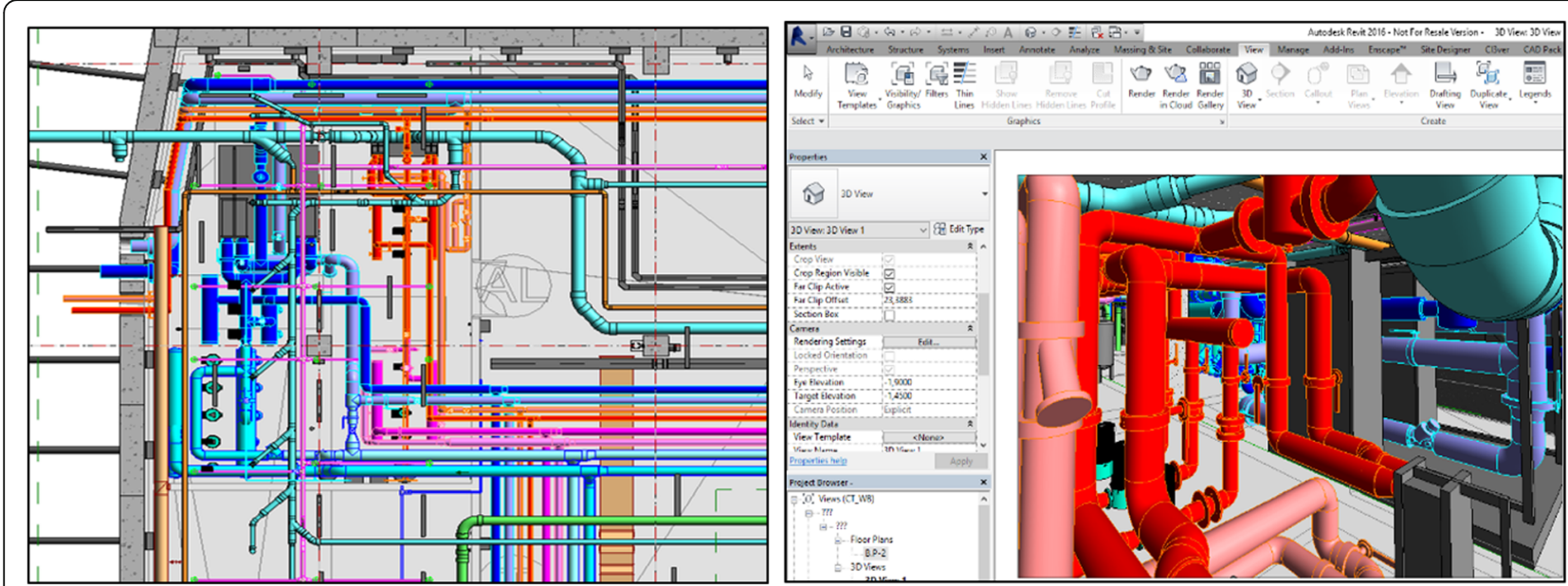

Fig. 4 Plan and Revit view of the MEP room. The MEP room features a large number of elements. In our experiment a simulation of a maintenance operation was conducted in VR

noticeable that on today's average computers, loading large sized Revit files may run the computer into crashes or slow performance, hence the models are often divided into smaller models or are segmented by Revit worksets. The software allows for two rendering modes of draft and realistic, and as it was about the architectural design review, we used the realistic mode. This would impose a tougher task on the computers graphic processing units (GPUs). There could be risks of crash, but as during this session only one user was in the VR scene, the experience was smooth. It was exciting for both the designers and the client to be immersed in the model and review the design with realistic feel of scale, dimensions and proportions. This level of perception of spatial relations before a project is built, is unique to VR as well.

\section{Evaluation results and discussions Observation from the experiment}

During the preparation stage, we learnt that it is extremely important to check the hardware and software of the computers to have an acceptable performance. In our first experiments, there were some degrees of latency in image rendering in the HMD which made it almost impractical. After updating graphic card drivers, we adjusted the settings of the HTC VIVE units to apply direct mode which ensures that the HMD is not recognized as a monitor. In addition, we replaced the analog connectors with HDMI ones for the output to the video projectors and the performance improved considerably. One common problem during VR practices can be the crash of software handling the VR scene, especially when the models are quite large. To avoid this, we applied

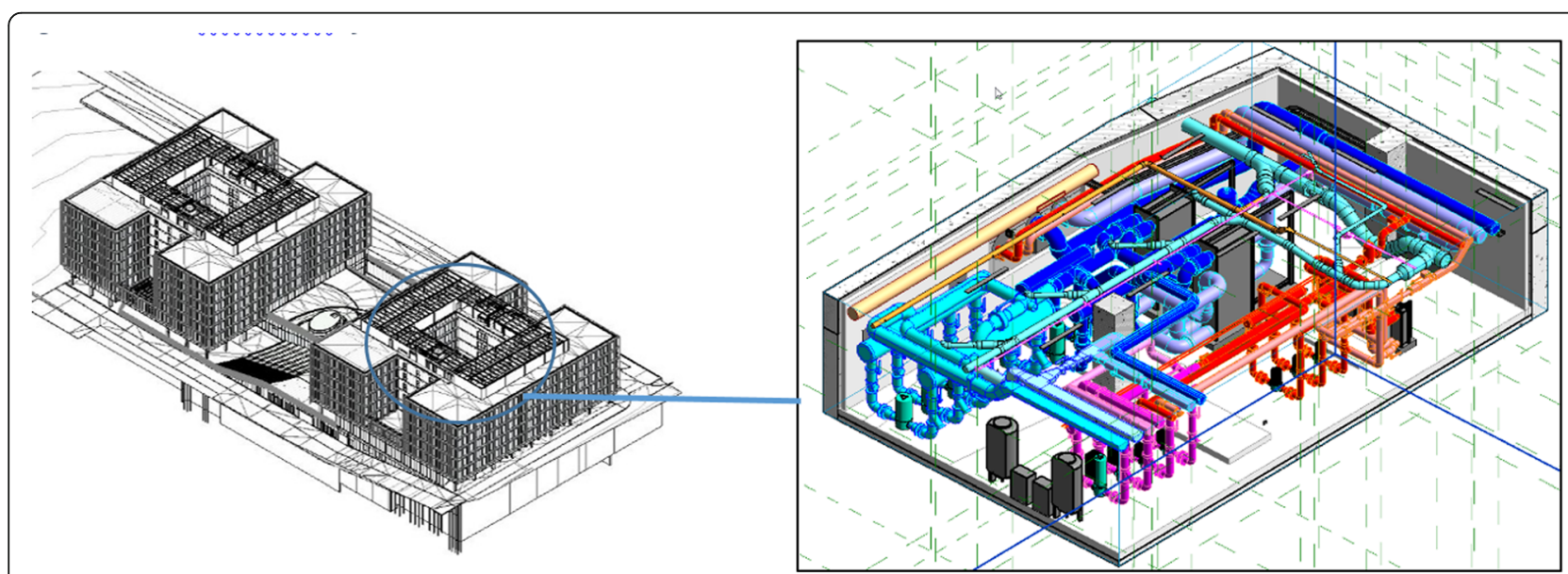

Fig. 5 The federated model, including all parts, and the mechanical room location. The federated model becomes very heavy for visualization purposes, even on potent machines. It is necessary to exclude all the parts that are not the subject of collaboration, before sending the geometry to a VR environment 


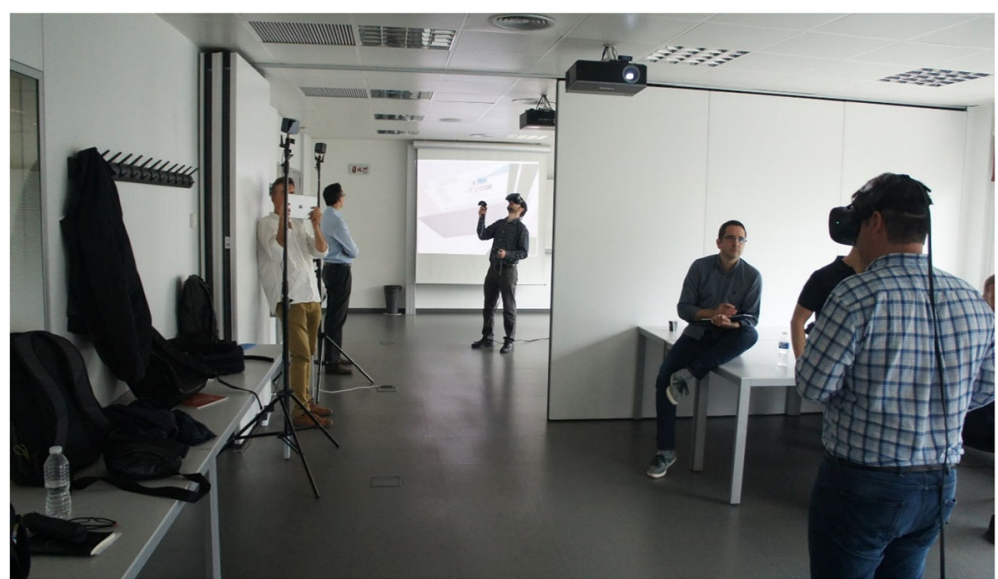

Fig. 6 Two participants collaborating in the same VR scene. A network feature of the software allows for hosting of multiple users in a VR scene. This abolishes the requirement of the physical presence of team members in the same location

section boxes in the Fuzor software, so only the parts of the model that were of our interest for specific activities were rendered. It can be said that the average hardware available in the market and the software currently able to run VR scenes for AEC file formats, are at an edge of operability. The computers that meet these preconditions can be quite costly and the averagely priced desktops or laptops currently used by consumers are not able to handle a VR experience. This can be considered as one the obstacles for the wide adoption of VR-based workflows in AEC.

Participants were fairly quick to learn how to interact with the model, and in a period of five minutes most of them were already comfortable with the devices and could perform the activities. Often shortly after starting the experiment, we could receive feedbacks and suggestions about the experience. The participants expressed what features and additions to the software could help them with performing activities in VR. We reported these feedbacks to the software company and they approved that they are working on implementing them for the coming releases. The newly released version of the software included a markup tool, one of our suggestions.

The practicality and advantages of a design review in VR was obvious to most of the participants, but there were doubts about its adoptability as a daily practice. A main concern was about the workflows of exporting a Revit model to a VR scene as they imagined there is a need for a great deal of preparation. They were informed that in fact, by available tools in the market this workflow has been simplified, some creating a VR scene with 1-click solutions directly from Revit. Actually, extensive efforts in software development companies are focused on homogenizing the workflows and processes in BIM enabled practices. Interoperability between software and automation of processes and easy-to-achieve outputs like renders and data are all helping AEC professionals doing more in their work.

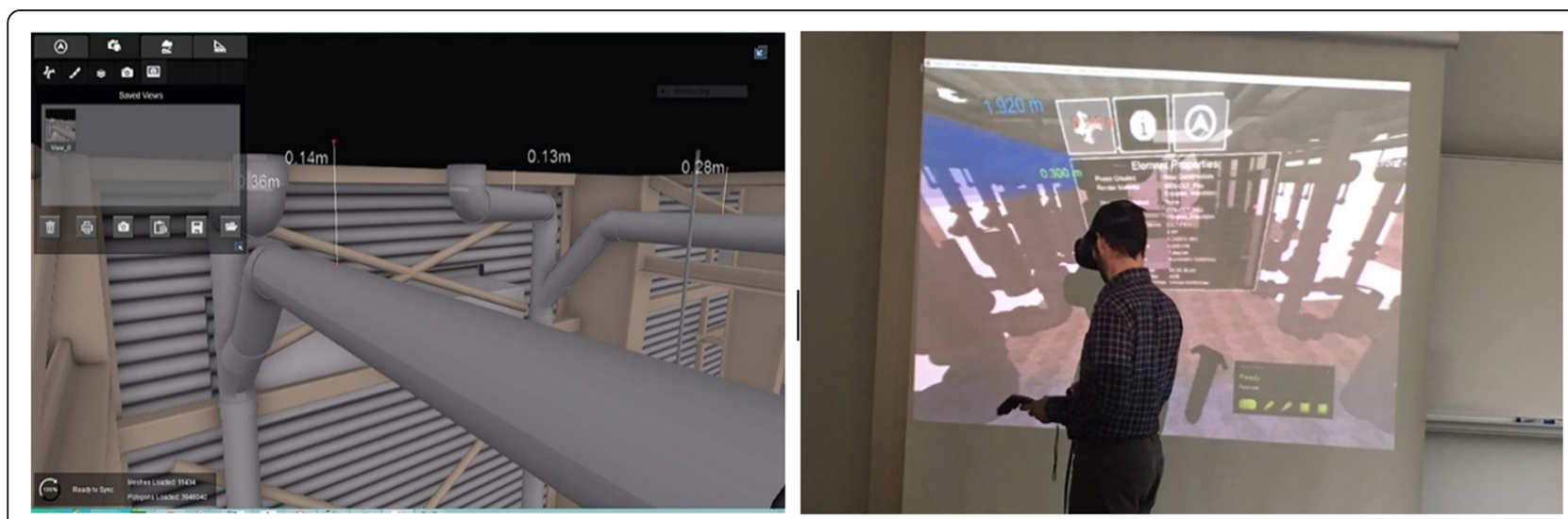

Fig. 7 Measurements placed between model elements in VR. A measurement tool in the software allows users to measure distances in the model and leave dimension marks. A user is seen using the tool and placing dimension by HTC Vive joysticks 

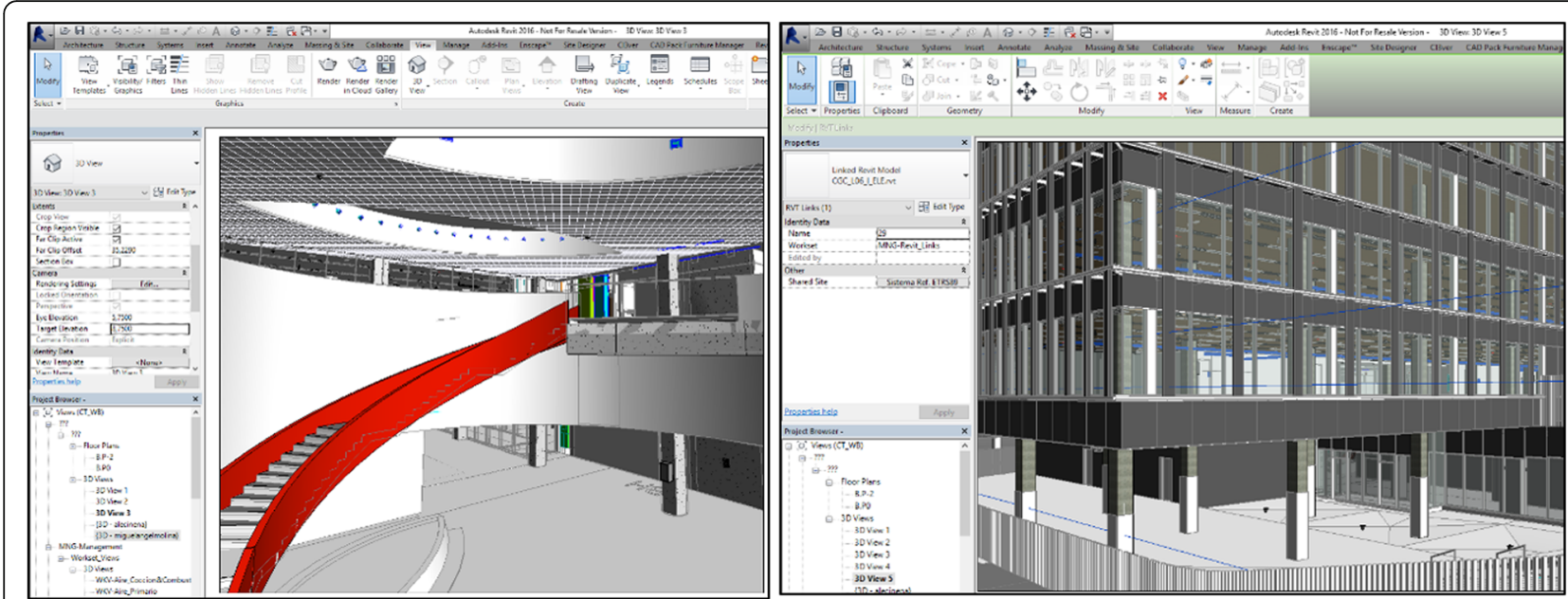

Fig. 8 Views of the parts of the building visualized in VR. Some parts of building that had spatial complexity or were about the façade and exterior look of the building were chosen for architectural design review. The architecture team presented the design in VR, to the client who also was immersed in VR

\section{Interview results}

To achieve the first-hand feedbacks from the participants, they were interviewed right after each one's experience. We had a web-based questionnaire that we filled with their answers which was visualized in the form of charts. We asked about the participants' and their firms' background, the experiment with VR and their thoughts about using it in future. We gathered feedback from nine participants who wore the VR HDMs and experienced the scene, and were all from AEC sector, but of very distant disciplines.

All the users had experience with BIM to some extent and near half of them are working in fully BIM enabled practices (Fig. 10).

The majority of the participants had no or little experience with VR before, and nearly all rated the experiment as very interesting (Fig. 11). One of our important questions was how practical do the participants see the daily use of VR in their offices. The average response was to some degree and for particular uses, while nobody found it not practical at all (Fig. 12). The responses came from a variety of professionals with very different daily tasks. Their level of knowledge about creating VR scene workflows could affect this response.

Some of the disadvantages usually mentioned with the use of VR are its discomfort, the physiological difficulties it may cause and the process of getting used to it. In this experiment, almost all the participants indicated that they were quickly, in a range of under five minutes, feeling adopted to the VR environment. About more than half of the participants felt very comfortable during the whole experience. The rest had felt some degrees of
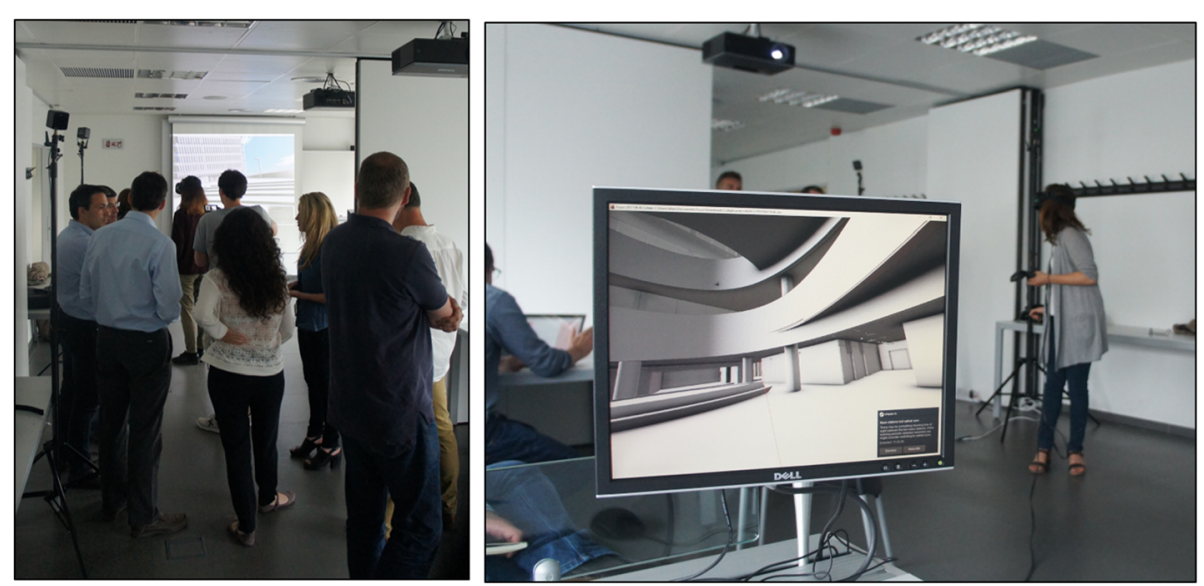

Fig. 9 Project stakeholders observing the Architectural design review session. During the experiment stakeholders from different disciplines were present and observed or participated in it. They were interviewed after the experiment 


\section{BIM implementation in your organization}

\section{9 responses}

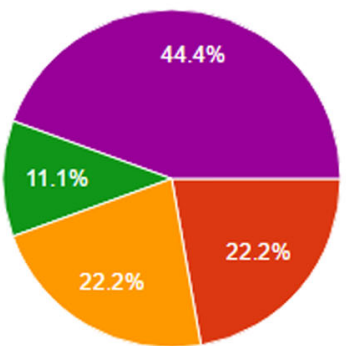

We have not implemented BIM at all

We have tested but not implemented yet

We are in the process of implementing BIM

We have already implemented BIM in some scale

We are a fully BIM-enabled practice

Fig. 10 BIM implementation statistics. We have not implemented BIM at all 0\%. We have tested but not implemented yet 22\%. We are in the process of implementing BIM 22\%. We have already implemented BIM in some scale 11\%. We are a fully BIM-enabled practice $44 \%$

motion sickness, have felt tired after some time wearing the HMD or found it difficult to move around with the device. About less than half of the participants found the process of getting used to the VR environment and devices very easy, while others expressed some degrees of difficulties for the process (Fig. 13).

The participants were asked to describe what features of the experiment were more impressive to them. Most of the answers were implying on the sensing and perceiving the space in real scale or as one participant said "the sensation of being inside the building". It is on the grounds that in VR the users not just visualize and view the model, but are inside or around it, resulting in a level of immersion unlikely possible by any other mediums. Having the ability to view the building elements information in VR and the speed and ease of movement inside the model were other impressive features to the participants.

Another important aspect of VR that we asked about, is its use cases and applications in different areas of AEC professionals' activities (Fig. 14). The participants were asked to rate the applicability of VR from not recommended to highly recommended in the following use cases: Internal design review with colleagues, personal use in office, internal collaboration, collaboration with other project teams, presentation to clients, project decision communication to site workers, simulation of a project issue (handicap access, etc.). The highest ranked use case was the presentation to the clients use case. Also collaboration with other teams and internal design review were use cases they would recommend the use of VR. Given that the participants were of different backgrounds with different levels of acquaintance to the VR software and tools available in the market, we asked them how they see the workflow of visualizing a BIM model in VR from 0 being easy and straightforward to 5 being difficult and burdensome. The majority indicated 3 in the range of difficulty and the rest found it easy and straightforward, with no one rating it as difficult and burdensome.

Following the questions about the experiment and the applicability of VR in AEC practices, we asked the participants what are the main obstacles for adopting VR as a tool in their activities. Some choices were given and moreover, they could express their own opinion about what they see as an obstacle. The highest rate goes to the software and hardware costs associated with VR implementation. No One saw its lack of application as a hurdle and some indicated the "resistance to change from personnel and firms" or the need of "knowledge of the technology and its scope" can be considered as barriers to the implementation of VR-based practices (Fig. 15).

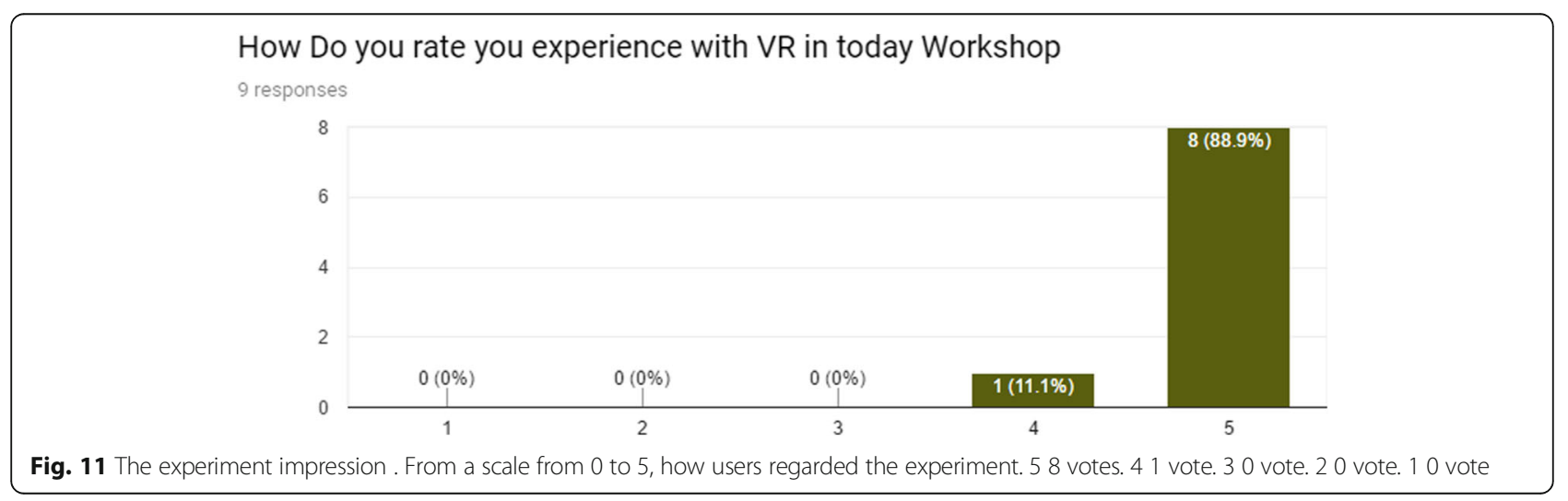




\section{How practical do you find VR in your daily practice \\ 9 responses}

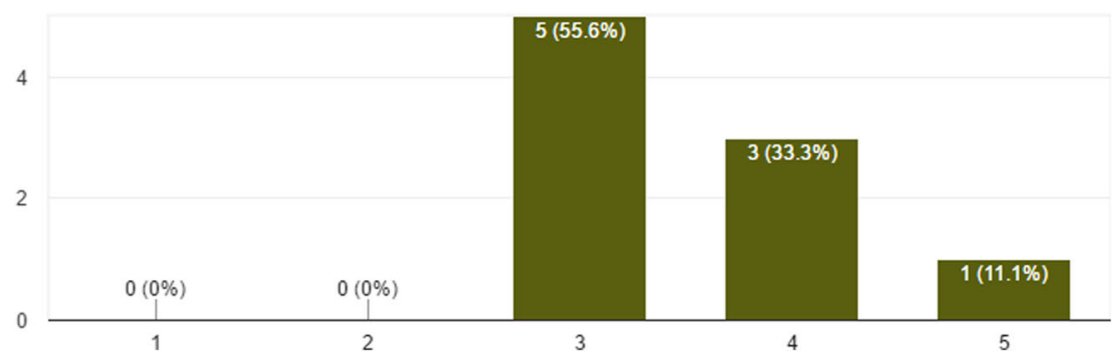

Fig. 12 The applicability of VR. From a scale from 0 to 5, how users voted how they see VR application as daily part of their practice. 51 vote. 4 3 votes. 35 votes. 20 vote. 10 vote

Our last question was about what features the participants would like to see in future VR tools. Some comments regarded the software we used for the experiment which were communicated to the software company, and some regarded what can be interesting to have in VR tools in general. One of the comments was on the "simulation of the behaviors of the building", for example the structural wind resistance being mapped on the model. Simulation and visualization of data on the model are currently practiced in BIM processes, most commonly are the solar and daylight studies or solar heat gains that can be visualized on a Revit model by available plugins, and to be able to see these kinds of visualizations in VR is definitely an added value.

\section{Conclusion}

\section{Findings}

This work addresses two issues of conventional BIM collaboration methods. First, the need of physical presence in methods such as Big BIM room and second, the lack of full immersion in model visualization. Furthermore, through a lived experiment, we evaluated a VR integrated collaboration workflow in a real project. This workflow supposedly could enable us to perform a clash-detection in MEP systems via simulation. The evaluation included some innovative feature of a VR software, allowing for virtual presence of multiple users and simulation of on-site tasks. An aspect of this work that makes it distinct from other experiments was that the participants were asked to perform task that they were already involved with at that time in their firms. Only that they were require to perform the tasks with VR as the visualization medium. This allowed them to do a direct and sensible comparison between a VR enabled workflow and their conventional ones.

A common problem in the maintenance of building systems is the accessibility to the MEP elements and the ease of repairing and replacing them. Through this live experiment we found out that VR has a practicality of addressing this issue by simulating a real situation. Although previous research might have suggested assumed use cases for VR in AEC, the particular feature of this software allowing for such simulation was put into an academic case study for the first time at the time of the experiment.

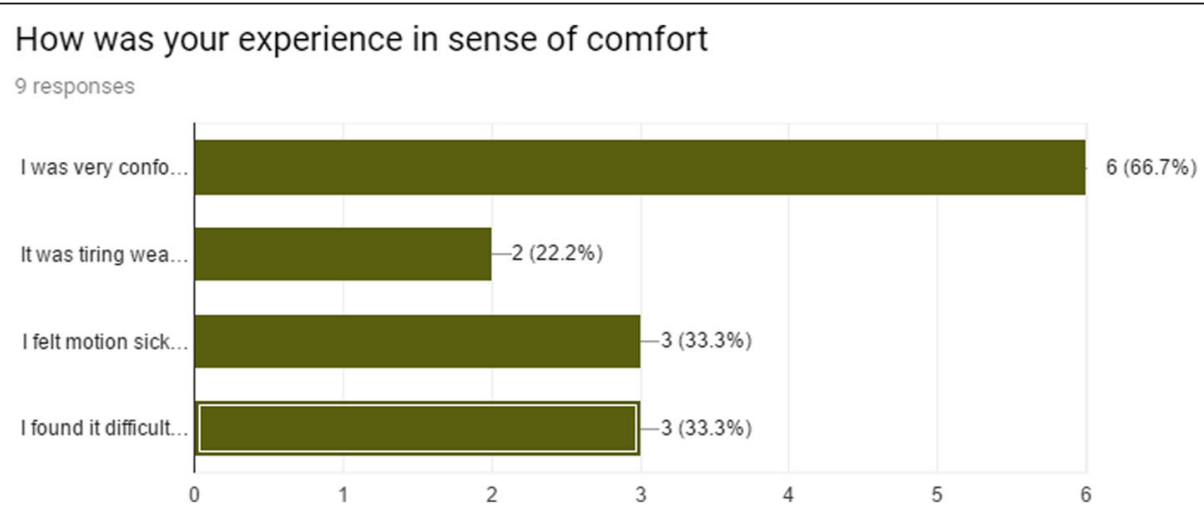

Fig. 13 Comfort feeling. Users chose one the statements regarding how comfortable they felt wearing the VR gears and being immersed in VR. I was very comfortable wearing headsets 6 votes. It was tiring wearing the headsets for some time 2 votes. I felt motion sickness after moving 3 votes. I found it difficult to move around with the headsets 3 votes 


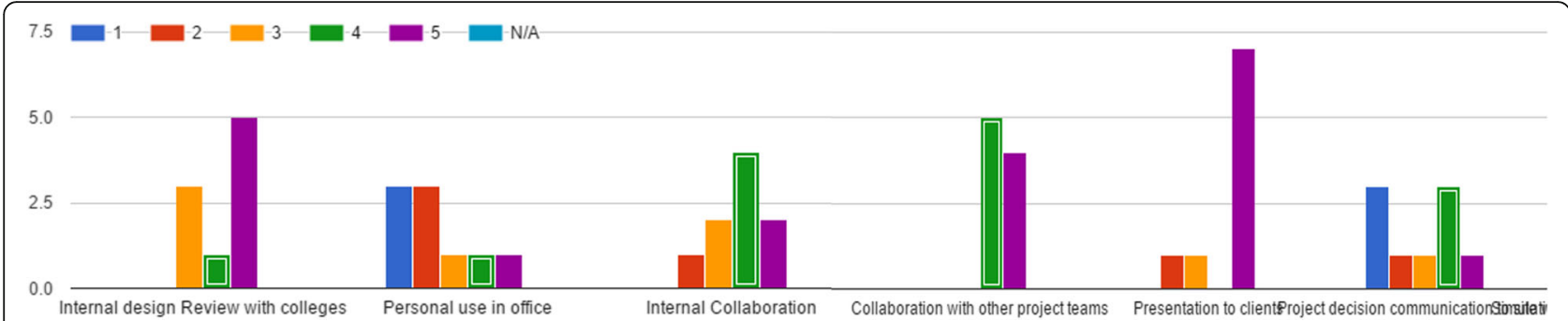

Fig. $14 \mathrm{VR}$ use cases. Uses voted from 1 (not recommended) to 5 (absolutely recommended) the applicability of VR in their practice. Internal design Review with colleges. 10 votes 20 votes 33 votes 41 vote 55 votes. Personal use in office. 13 votes 23 votes 31 votes 41 vote 51 votes. Internal Collaboration. 10 votes 21 votes 32 votes 44 votes 52 votes. Collaboration with other project teams. 10 votes 20 votes 30 votes 45 votes 54 votes. Presentation to clients. 10 votes 21 votes 31 votes 40 vote 57 votes. Project decision communication to site workers.. 13 votes 21 votes 31 votes 43 vote 51 votes

It was resulted from the interviews participants believe such simulation can be practical in addressing the issue, although they suggested some software functionality to make it more practical. New releases of the software included features such as a permanent markup tool based on our suggestions. In addition, we found out that the awareness factor, also highlighted as a major factor in BIM adoption, also play a key role for employing VR tools in AEC practices. Most of our participant had no or little experience with VR and did not consider it a functional tool in their practice. The interview results showed that after their experience they would consider the use of VR in their workflow.

\section{Conclusion}

At the heart of the BIM collaboration workflows lays the visualization of a $3 \mathrm{D}$ model based on which the AEC professionals can review the designs, encounter clashed and errors and visually communicate project decisions to other stakeholders. BIM authoring tools such as Revit are meant to be used for creating and authoring the models. It means they are not always suitable for visualizing the model for presentational and design review purposes, due to their slow performance while interacting with model. Furthermore, for model privacy concerns it is not always desirable to share the model file. Third party software should be usually used for specific visualizing purposes.

Creating the virtual environment relies heavily on the software available in the market and the features they offer. The more the software are adoptable and compatible with current BIM workflows and file formats used by a firm, the higher their practicality. The functionality of VR tools for AEC practices, depends on the tools and features the software offer. Some tools are merely visualizers of a BIM model, while others allow degrees of interactions with model and the ability to draw or add elements in the VR scene. It is important for the software companies to have a correct understanding of AEC needs to develop tools that meet those requirements.

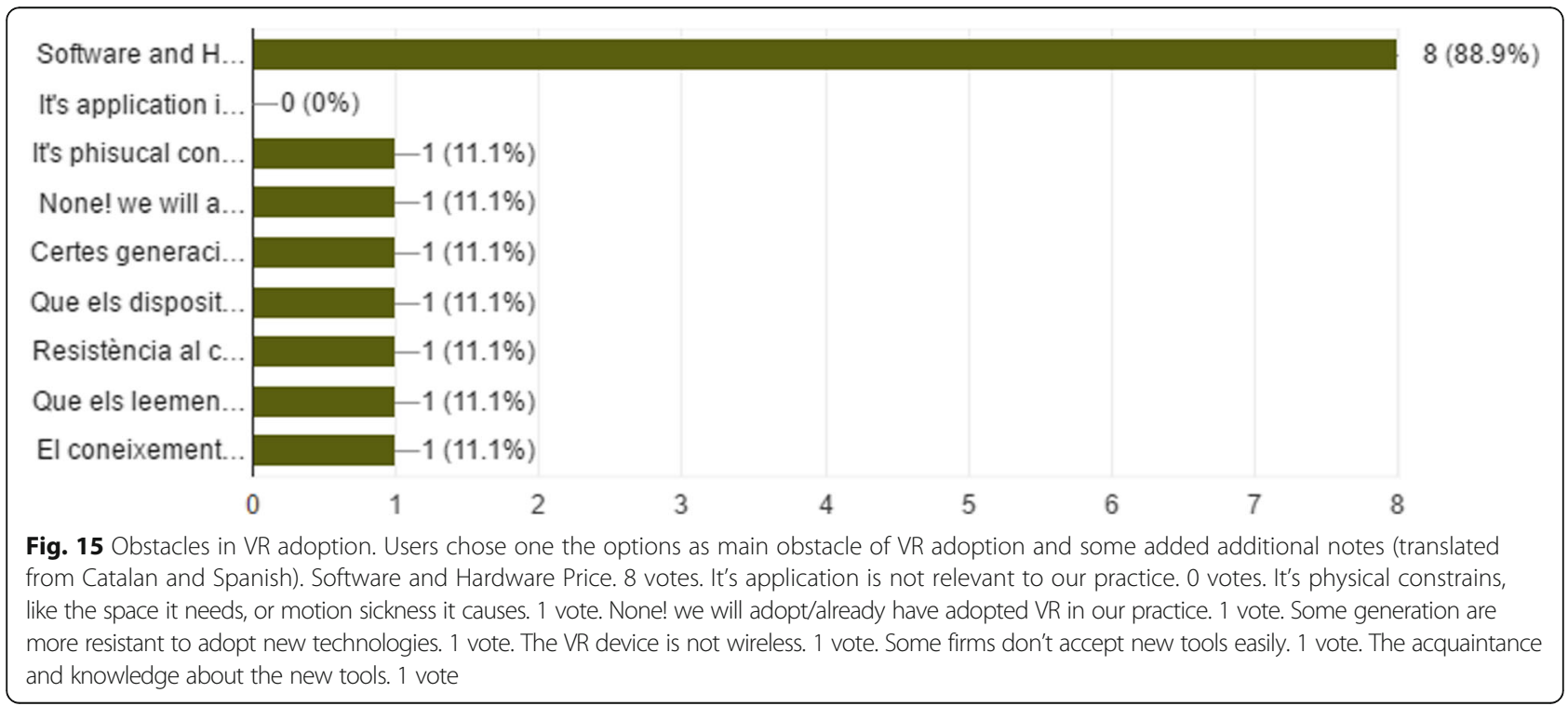


Investment in software and hardware is an essential step towards the adoption of VR. Computers with highly potent GPUs, that cost considerably, are necessary for handling VR scenes. Most of the software available are monthly or yearly subscription based and cost per user. The need for these investments often is an obstacle of VR adoption.

VR is a whole new realm in the cyber world and future works must be focused on realizing its capabilities and the opportunities it brings. By understanding the AEC needs and practices and developing software with features responding to those needs, the potential advantages of VR implementation in AEC can be discovered and evolved.

Future works in the field must be focused on two aspects, improvements and education. Improvements are needed in VR software to run on more conventional computers and to handle more complex models with acceptable performance. Research in the field of computer graphics done by the industry or academics can considerably contribute to such improvements. The education aspect refers to the importance of awareness within the professionals and current students. Architectural and engineering education and in particular BIM education must include topics on the potentials of VR and other innovative visualization tools from which AEC industry can benefit. With more practical tools and advanced taught skills we will be able to see new workflows and possibilities in the industry practices.

\section{Abbreviations \\ AEC: Architecture, engineering and construction; BIM: Building information modeling; GPU: Graphic processing unit; LOD: Level of detail; HMD: Head mounted device; ICT: Information and communication technology; MEP: Mechanical, electrical and plumbing; UPC: Polytechnic university of Catalonia; VR: Virtual reality}

\section{Acknowledgements}

We would like to thank UPCschool management and staff for providing us with the software licenses, hardware and the location to perform the experiment. Also to all the participants of the workshop, specially CT engineers and their collaborators in the project including Elecnor+Alainsa and Batlle i Roig. Also to Montse Armengol for her helps with organizing the different stages of the study.

\section{Funding}

UPCschool has funded the discounted license fee for Fuzor, the software used in the study. Kalloc Studios, developers of Fuzor, has discounted their license fee for academic purposes.

\section{Availability of data and materials}

Please contact author for data requests.

\section{Authors' contributions}

Reza Zaker has done the following contribution:- Studying the articles and other works done in the fields related to the article.- Establishing the theoretical background, finding the areas of interest to the study.- Studying the software available in the market and collaborating with the software developers to participate in the study. -Collaborating with engineering firms and studied their common practices in order to design the case study.Training the case study participants about the use of Virtual Reality hardware and software.-Preparing and conducting the workshop (experiment) of the case study.-Preparing and writing down the manuscript and the inclusion of references.-Revision of the manuscript. Eloi Coloma has done the following contributions:- As a teaching member of UPCschool, providing the funds and facilities offered by UPCschool.- Organizing the various firms and individuals involved in the case study.- Interviewing the participants of the workshop.- Helping with establishment of where the study is placed and the preparation of the workshop. -Revision of the manuscript. All authors read and approved the final manuscript.

\section{Authors' information}

Reza Zaker is a PhD candidate at Universitat Politècnica de Catalunya. His thesis research investigates the impact of BIM implementation on architectural practices. He has collaborated with CL3VER, a software company, in the development of a new range of real-time rendering and visualization tools. Reza has been the product manager of a BIM visualization tool, tailoring the core visualization technology for AEC applications. This collaboration made him familiar with many aspects of the development of visualization software, the technologies involved, the market and the opportunities that real-time and virtual reality engines bring the construction industry.

Eloi Coloma PhD is a lecturer at Universitat Politècnica de Catalunya. He is currently the director of a Master program about BIM steering management in UPCschool, a subdivision of Universitat Politècnica de Catalunya that offers specialized courses aimed at professionals. He has been working with many firms and individuals through their journey in BIM adoption. He is a well known figure in his native Catalunya in the field of BIM.

\section{Competing interests}

The authors declare that they have no competing interests.

\section{Publisher's Note}

Springer Nature remains neutral with regard to jurisdictional claims in published maps and institutional affiliations.

Received: 18 April 2018 Accepted: 12 September 2018

Published online: 27 September 2018

\section{References}

Adamu, Z. A., Emmitt, S., \& Soetanto, R. (2015). Social BIM: Co-creation with shared situational awareness. The Journal of Information Technology in Construction (ITcon), 20, 230-252.

BIM Guidelines. 2012. New York City Department of design + construction.

Bond Ralph, 2017 . area.autodesk.com/blogs/buildings-in-motion/from-3ds-maxto-vr.

BIM Task Group, 2013. https://www.bsigroup.com/en-GB/about-bsi/media-centre/ press-releases/2016/april/New-BIM-Level-2-website-launches/.

Bouchlaghem, D., Shang, H., Whyte, J., \& Ganah, A. (2005). Visualisation in architecture, engineering and construction (AEC). Automation in Construction, 14, 287-295.

Brooks, F. P. (1993). Virtual reality--hype or Hope: What's real? In proceedings of the IEEE symposium on research Frontiers in virtual reality (p. 3).

Bushnell, T., Lehtinen, T., Kokkonen, A., Lavikka, R., Neelappa, A., \& Senescu, R. (2013). Collaboration and contracts in integrated project delivery-exploring the roles of owners and architects, in: The boundary-crossing conference on coDesign in Innovation. Espoo: Presented at the Co-create.

CAT 2017 GUIA BIM PER A LA GESTIÓ DE PROJECTES I OBRES. Infraestructrura.

Colin, G., \& Hughes, W. (2007). Building Design Management. Oxford: ButerworthHeinemann.

CURT. (2005). Optimizing the construction process: An implementation strategy. Cincinnati: Construction Users Roundtable.

Dave, B., Koskela, L., Kagioglou, M., \& Bertelsen, S. (2008). A Critical Look at Integrating People, Process and Information Systems Within the Construction Sector. In P. Tzortzopoulos \& M. Kagioglou (Eds.), 16th Annual Conference of the International Group for Lean Construction.Manchester (pp. 795-808).

Dave, B., Koskela, L., Kiviniemi, A., Tzortzopoulos, P., Owen, R.L., 2013. Implementing lean in construction : Lean construction and BIM.CIRIA.

Dörner, R., Brot, W., Grimm, P., \& Jung, B. (Eds.). (2013). Virtual und Augmented Reality, Grundlagen und Methoden der Virtuellen und Augmentierten Realität. Berlin/Heidelberg: Springer.

Eastman, C., Teicholz, P., Sacks, R., \& Liston, K. (2011). BIM handbook: A guide to building information modelling for owners, managers, designers, engineers and contractors. New Jersey: Wiley. 
Farzad Pour Rahimian, Tomasz Arciszewski, Jack Goulding, (2014) Successful education for AEC professionals: case study of applying immersive game-like virtual reality interfaces. Visualization in Engineering 2 (1):4.

Goulding, J. S., Rahimian, F. P., \& Wang, X. (2014). Virtual reality-based cloud BIM platform for integrated AEC projects. Journal of Information Technology in Construction, Special Issue BIM Cloud-Based Technology in the AEC Sector: Present Status and Future Trends, 19, 308-325.

Hartmann, T. (2008). A GrassrootsModel of Decision Support System Implications by Construction Project Teams. Ph.D. thesis. Stanford University.

HTC corporation. VIVE ready computers, 2017. https://www.vive.com/au/ready/.

Isikdag, U., \& Underwood, J. (2010). Two design patterns for facilitating building information model-based synchronous collaboration. Automation in Construction, 19(5), 544-553.

Koskela, $\sqcup$ and Kazi, AS 2003, 'Information technology in construction: How to realise the benefits?', in: Sociotechnical and human cognition elements of information systems.

Kreutzberg, A. (2015). 'Conveying architectural form and space with virtual Reality', real time - proceedings of the 33rd eCAADe conference 2015 (pp. 117-124). Vienna.

Liu, Y., et al. (2016). Understanding effects of BIM on collaborative design and construction: An empirical study in China. International Journal Project Management.

Marshall, C., \& Rossman, G. B. (1989). Designing qualitative research. Newbury Park: Sage.

McGraw-Hill. (2012). Buisness Value of BIM in North America SmartMarket Report.

McGraw Hill Construction (2014). The business value of BIM for construction in major global markets: How contractors around the world are driving innovation with Building Information Modelling,

Miltiadis, C. (2016). Virtual architecture in a real-time, interactive, augmented reality environment Rasmussen, SE 1959, 1980 edn. Cambridge: Experiencing Architecture, The MIT Press.

Moss, J. D., \& Muth, E. R. (2011). Characteristics of head-mounted displays and their effects on simulator sickness. Human Factors: The Journal of the Human Factors and Ergonomics Society, 53(3).

Owen M., Grant L., Sayers S. and Facer K. (2006). Social software and learning, Futurelab, Vol. 1, No. 71

Porwal, A., \& Hewage, K. N. (2013). Building information modeling (BIM) partnering framework for public construction projects. Automation in Construction, 31, 204-214.

Raisbeck, P., Millie, R., \& Maher, A. (2010). Assessing integrated project delivery: A comparative analysis of IPD and alliance contractingprocurement routes. Management, 1019, 1028.

Rasmussen, S. 1959. Experiencing Architecture. Cambridge: MIT Press.

Roupé, M. (2013). Development and implementations of virtual reality for decisionmaking in urban planning and building design. Chalmers University of Technology.

Sackey, E., Tuuli, M., \& Dainty, A. (2014). Sociotechnical systems approach to BIM implementation in a multidisciplinary construction context. Journal Management Engineering Spec. Issue.

Schmitt, G. (1993). Virtual reality in architecture. In N. M. Thalmann \& D. Thalmann (Eds.), virtual worlds and multimedia (pp. 85-97).

Singh, V., Gu, N., \& Wang, X. (2011). A theoretical framework of a BIM-based multi-disciplinary collaboration platform. Automation in Construction, 20(2), 134-144.

Swider Matt ,2017. HTC Vive vs Oculus Rift: which VR headset is better? http://www. techradar.com/news/wearables/htc-vive-vs-oculus-rift-1301375

Van Nederveen, G. A., \& Tolman, F. P. (1992). Modelling multiple views on buildings. Automation in Construction, 1(3), 215-224.

Waters Janet , 2016 Phenomenological Research Guidelines. 2000 revised

Whyte, J. (2002). Virtual reality and the built environment. Oxford: Architectural Press.

Yin Robert K. , 2009. Case study research: Design and methods.

\section{Submit your manuscript to a SpringerOpen ${ }^{\circ}$ journal and benefit from:}

- Convenient online submission

- Rigorous peer review

- Open access: articles freely available online

- High visibility within the field

- Retaining the copyright to your article

Submit your next manuscript at $\boldsymbol{\nabla}$ springeropen.com 